\title{
Molecular determinants of context-dependent progesterone receptor action in breast cancer
}

\author{
Christy R Hagan and Carol A Lange*
}

\begin{abstract}
The ovarian steroid hormone, progesterone, and its nuclear receptor, the progesterone receptor, are implicated in the progression of breast cancer. Clinical trial data on the effects of hormone replacement therapy underscore the importance of understanding how progestins influence breast cancer growth. The progesterone receptor regulation of distinct target genes is mediated by complex interactions between the progesterone receptor and other regulatory factors that determine the context-dependent transcriptional action of the progesterone receptor. These interactions often lead to post-translational modifications to the progesterone receptor that can dramatically alter receptor function, both in the normal mammary gland and in breast cancer. This review highlights the molecular components that regulate progesterone receptor transcriptional action and describes how a better understanding of the complex interactions between the progesterone receptor and other regulatory factors may be critical to enhancing the clinical efficacy of anti-progestins for use in the treatment of breast cancer.
\end{abstract}

Keywords: Breast cancer, Post-translational modifications, Progesterone receptor, Signal transduction

\section{Introduction}

The mitogenic activity of estrogen is well established, but an under-studied ovarian steroid hormone, progesterone, is emerging as a primary mitogen in the breast, contributing significantly to genetic programming required for mammary stem cell self-renewal, mammary gland development, proliferation, and hyperplasia [1]. The effects of progesterone are triggered after binding of progesterone to its intracellular receptor, the progesterone receptor (PR). The PR exists in two primary isoforms, differing structurally by the inclusion of an $\mathrm{N}$-terminal segment unique to the fulllength isoform, PR-B [2] (Figure 1). This region, termed the B-upstream segment, is missing from the shorter isoform, PR-A [3]. The two isoforms are encoded by the same gene (regulated by distinct but tandem upstream promoters) and are most often co-expressed [4]. The PR is a member of the steroid hormone receptor subgroup of ligand-activated transcription factors within the large nuclear receptor superfamily, and is an important down-stream effector of estrogen-receptor (ER) signaling; in most circumstances, estrogen is required for robust PR expression. PR binding

\footnotetext{
* Correspondence: lange047@umn.edu

Department of Medicine (Hematology, Oncology, and Transplantation) and the Department of Pharmacology, University of Minnesota, Masonic Cancer Center, 420 Delaware St SE, MMC 806, Minneapolis, MN 55455, USA
}

to DNA, either directly through progesterone response elements or indirectly through tethering interactions with other transcription factors, activates transcriptional profiles associated with mammary gland proliferation and breast cancer [5-9]. Additionally, PR binding interactions with transcriptional co-activators and repressors are critical to PR transcription factor function [10].

PRs are highly post-translationally modified, primarily through N-terminal phosphorylation (select phosphorylation sites most relevant to breast cancer biology are highlighted in Figure 1), acetylation, SUMOylation, and ubiquitination [9,11-17]. These receptor modifications dramatically alter PR function, receptor localization and turnover, and promoter selectivity. The PR can be phosphorylated basally in the absence of the hormonal ligand, but is potently modified after ligand treatment, in response to local growth factors or in a cell cycle-dependent manner [12,13,15-17] (G. Dressing and C. Lange, unpublished data). Mitogenic protein kinases - such as CDK2, CK2, and MAPK - have been shown to phosphorylate PR and subsequently modify PR action. Therefore, PR can be thought of as a 'mitogenic sensor' in the cell, with PR phosphorylation serving as a readout of kinase activity. Highly mitogenic environments like cancer, where kinase activities are frequently high, may be a situation where PR is persistently phosphorylated in 


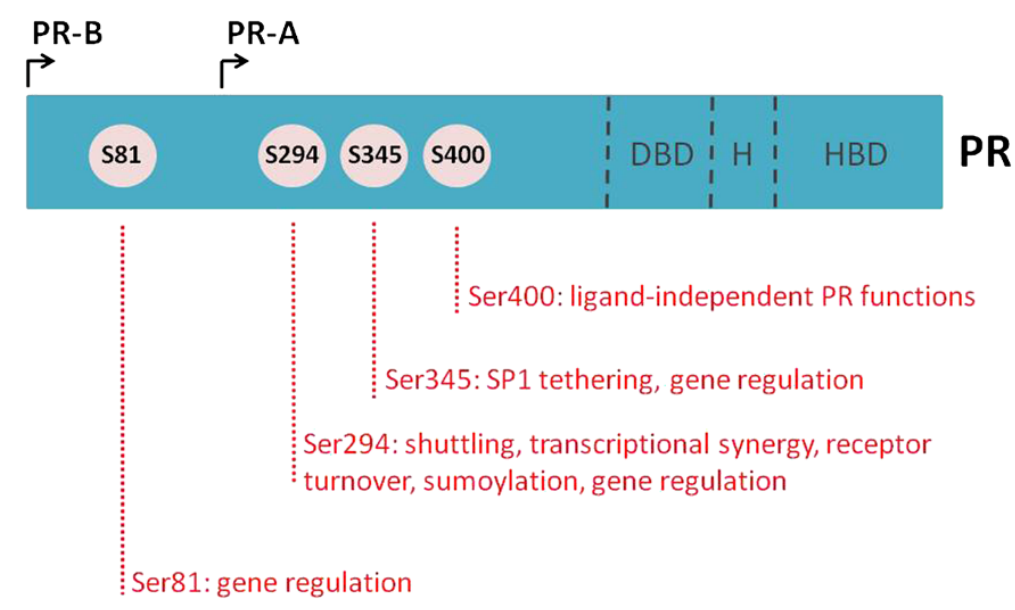

Figure 1 Schematic of progesterone receptor structure and select phosphorylation sites. Progesterone receptor (PR) isoforms A and B differ in their inclusion of an N-terminal upstream segment unique to PR-B. Both isoforms contain an identical DNA binding domain (DBD), hinge region $(H)$ and hormone binding domain (HBD). Full-length PR-B contains 14 phosphorylation sites; serines 81, 294,345 and 400 have known links to $\mathrm{PR}$ action and gene expression in breast cancer.

the absence of ligand. Moreover, in this case, mitogenic signals (that is, growth factors) may diminish or replace the need for ligand, thus activating PRs inappropriately.

In addition to receiving direct inputs from protein kinases via phosphorylation, PR interacts with and activates members of cytoplasmic signaling cascades, such c-SRC $[18,19]$. These rapid signaling actions of PR (previously termed non-genomic actions) are independent of PR's DNA-binding transcriptional activity [19]. However, direct PR interactions with components of kinase cascades and subsequent signaling pathway activation are highly integrated with PR genomic actions. Indeed, kinases that modify PR, as well as other growth factor-activated kinases, have been found in association with DNA-bound (that is, phosphorylated) PRs that function as part of the same transcription complexes that regulate PR-target gene promoters and enhancers $[16,20,21]$. Increasing knowledge about post-translational PR modifications and PR-modifying binding partners suggests that these events (such as phosphorylation, SUMOylation, and so on) are required for context-dependent activation of PR.

Understanding PR action is of great clinical significance in breast cancer, as evidenced by large-scale clinical trials conducted more than 10 years ago that demonstrated that PR actions fuel breast cancer growth. In two independent trials, women whose hormone-replacement therapy (HRT) regimens included estrogen and synthetic progesterone (that is, medroxyprogesterone acetate, norethisterone, or norgestrel/levonorgestrel) had a higher risk of developing breast cancer than women whose regimens included only estrogen and no progestins $[22,23]$. The results of these trials remain controversial for several reasons, including the fact that study participants were well past the onset of menopause when HRT was initiated.
Additionally, although synthetic progestins clearly closely mimic progesterone in vitro, some synthetic progestins (medroxyprogesterone acetate) may alter androgen receptor (AR) [24] or glucocorticoid receptor (GR) [25] signaling, exhibit different half-lives, and are metabolized differently than natural progesterone, and therefore may be associated with different breast cancer risks relative to their naturally occurring counterparts [26,27]. Finally, continuous dosing of progestins as part of HRT may fail to mimic cyclical lifetime exposure to natural ligand in vivo. However, taken together, these landmark clinical studies implicate PR in human breast cancer development and progression, a finding that is well-supported by animal studies $[28,29]$. It is thus important to fully understand how activated PRs may contribute to early breast cancer progression, perhaps by driving the transition from steroid receptor (SR)-positive tumors with better clinical prognoses to more aggressive, poorer outcome SR-negative and luminal-B-type tumors.

Convincing preclinical and clinical evidence suggests that progestins increase breast cancer risk in part by driving the proliferation of early lesions [28,30-35]. Even so, at least five main sources of confusion remain regarding the role of PR actions in breast cancer (expanded on in Box 1). First, PR action is context dependent - that is, PR action differs in normal versus neoplastic tissue and according to hormone exposure (for example, in the presence versus absence of estrogen), as well as organ site (for example, proliferative in the breast versus inhibitory in the uterus). Moreover, despite convincing progestin-dependent proliferative responses in murine models [32,36,37], early reports showed that progesterone was anti-proliferative or non-proliferative in human cells [38-40]. However, recent work from the laboratory of C. Brisken [41] has 
shown that progesterone is proliferative in human breast tissue microstructures isolated from normal human breast specimens. Interestingly, progesteronedependent proliferation and signaling is preserved only when the tissue architecture remains intact; human tissues (previously dissociated) grown in two- or threedimensional cultures did not display this proliferative phenotype, suggestive of further context-dependent PR actions. Second, PR isoform-specific activities (PR-A versus $P R-B)$ overlap but can have very disparate activities within a given target tissue and at selected gene promoters; however, despite their distinct activities, the two PR-isoforms are not distinguished clinically. Third, ligandindependent (that is, growth factor- or kinase-dependent) activities of PR are poorly understood. Fourth, the dosing (cyclical versus continuous) and source (natural versus synthetic) of ligand are likely to be key determinants of the kinetics of PR action. Fifth, although anti-progestins showed clinical promise in early clinical trials, their use was limited by liver toxicities (onapristone; [42]) largely attributable to cross-reactivity with other nuclear receptors, such as GR. This review will focus on the molecular determinants of PR's context-dependent actions and their clinical significance. These PR actions are primarily determined by the availability of PR-binding partners and direct modifications to PR that dictate promoter selection.

\begin{tabular}{l} 
Box 1: Complexities of progesterone receptor actions. \\
\hline - Tissue-specific effects (breast vs. reproductive tract) \\
- Actions in normal vs. neoplastic tissues \\
- Isoform-specific actions (PR-A vs. PR-B) \\
- Lack of clinical designation between PR isoforms \\
- Ligand-independent actions \\
- Timing of hormone delivery (continuous vs. cyclical) \\
- Source of hormone (synthetic vs. natural progesterone) \\
- PR actions are both ER-dependent and ER-independent \\
- Efficacy of early anti-progestins in the clinic
\end{tabular}

Post-translational modifications and molecular interactions alter promoter selectivity

Mounting evidence suggests that post-translational modifications of PR are key determinants of promoter selectivity and, in turn, the spectrum of target genes activated in response to ligand binding (reviewed in $[43,44]$ ). PR promoter preference is partially dictated by differences in the recruitment of $\mathrm{PR}$ and/or its co-activators or corepressors to specific DNA sequences. In microarray analyses, cells expressing wild-type PR or PRs containing single point-mutations at specific phosphorylation or SUMOylation sites exhibit dramatic changes in
PR-dependent gene expression, specific to precise post-translational modifications. For example, recent analyses from the Lange laboratory revealed that PR phosphorylation on serine 294 favors the subsequent deSUMOylation on PR lysine 388 [45], thereby yielding a hyperactive receptor that regulates a unique gene expression signature found in high ERBB2-expressiong tumors; this unique phospho-PR gene expression signature predicted decreased survival in patients treated with tamoxifen [9]. By contrast, a separate gene expression pattern is observed when PR is phosphorylated on Ser81 by $\mathrm{CK} 2$, a kinase commonly overexpressed in breast cancers; this modification is associated with the expression of gene sets involved in interferon and STAT5 signaling (discussed in more detail below) [8]. Therefore, in response to ligand, growth factor-mediated PR phosphorylation (or phosphorylation-dependent alterations of other posttranslational modifications such as SUMOylation) dictates the selective expression of specific subsets of target genes and subsequently their transcriptional programs.

Target gene selectivity is achieved not only through differential recruitment of PR $[8,16]$, but also through associated transcriptional co-activators and repressors that are critical to PR function $[9,10,46]$. For example, pioneer factors are specialized subsets of transcription factors that open defined regions of chromatin, making it accessible for other transcription factors, like SRs (reviewed in $[47,48]$ ). These types of factors have been identified for other nuclear receptors, such as ER and AR; however, they have yet to be identified for PR. Preliminary data suggest that FOXA1 and STAT5 may be putative pioneer factors for PR $[8,49,50]$; differential binding interactions between PR and these factors provide a mechanism for promoter selectivity, perhaps based on PR post-translational modifications (that is, via phosphorylation-specific interactions with pioneer factors).

Emerging evidence suggests that interactions between members of the SR superfamily is an additional regulatory step in determining target-gene specificity. Interactions between ER and AR have been the focus of recent investigations [51,52]. Recent data from the Lanari group demonstrate the existence of functional cross-talk between ER and PR; both receptors are localized together on regulatory regions of PR-target genes, such as CCND1 and $M Y C$, primarily in response to treatment with progestins [53]. Moreover, work recently published from our group suggests a complimentary story whereby ER and PR cooperate to regulate a subset of ER-target genes in response to estrogen, but fully independent of exogenously added progestin. In this case, PR-B appears to act as a scaffolding molecule for increased recruitment of signaling adaptors and protein kinases that phosphorylate ER within ER/PR-containing transcription complexes [54]. Taken together, these studies suggest that contextdependent progesterone/PR action may in part depend 
on the presence of other steroid hormones and their receptors. Detailed biochemical studies of steroid hormone receptor cross-talk are needed to provide a framework for a better understanding of differential hormone actions in pre- and post-menopausal conditions where endogenous hormone levels dramatically differ, as well as during breast or prostate cancer treatment with hormoneablation therapies where closely related steroid hormone receptors (PR, GR, AR, ER) may substitute for the blocked activity of another (ER or AR).

\section{Progesterone receptor phosphorylation by CK2 as a paradigm for receptor modification and regulation}

Recent data from our laboratory characterizing PR phosphorylation on Ser81 by CK2 exemplifies how the aforementioned modifications and signaling inputs can alter PR function. CK2 is a ubiquitously expressed kinase often up-regulated in many different types of cancer, including breast [55-57]. We and others have shown that CK2 phosphorylates PR on Ser81, a site that is basally phosphorylated; however, Ser 81 phosphorylation levels increase markedly in response to ligand (or when cells enter $\mathrm{S}$ phase in the absence of ligand) $[16,58]$. PR phosphorylation at Ser81 is associated with a specific gene expression profile, which is correlated with pathways altered in breast cancer, including genes implicated in mammary stem cell maintenance and renewal $[8,16]$. Additionally, the PR target genes whose expression require phosphorylation at Ser81 are significantly associated with interferon/inflammation and STAT-signaling datasets, a unique observation for SRs that represents a novel link between steroid hormone action, inflammation, and cancer [8]. A key target gene regulated by Ser81 phosphorylation is STAT5 itself, and notably, JAK/STAT signaling is required for potent activation of PR Ser81-regulated genes, indicating a feed-forward mechanism for gene program activation (Figure 2). STAT5 is present, along with phosphorylated PR, on the regulatory region of WNT1, a key Ser81 target gene known to be involved in cancer and stem cell biology. Moreover, an in silico analysis of a publically available PR whole genome chromatin immunoprecipitation dataset reveals that there is significant enrichment of STAT5 consensus sites within PR-bound chromatin regions, indicating that STAT5 may function as a pioneer factor for phosphorylated PR (perhaps specifically when PR Ser81 is phosphorylated).

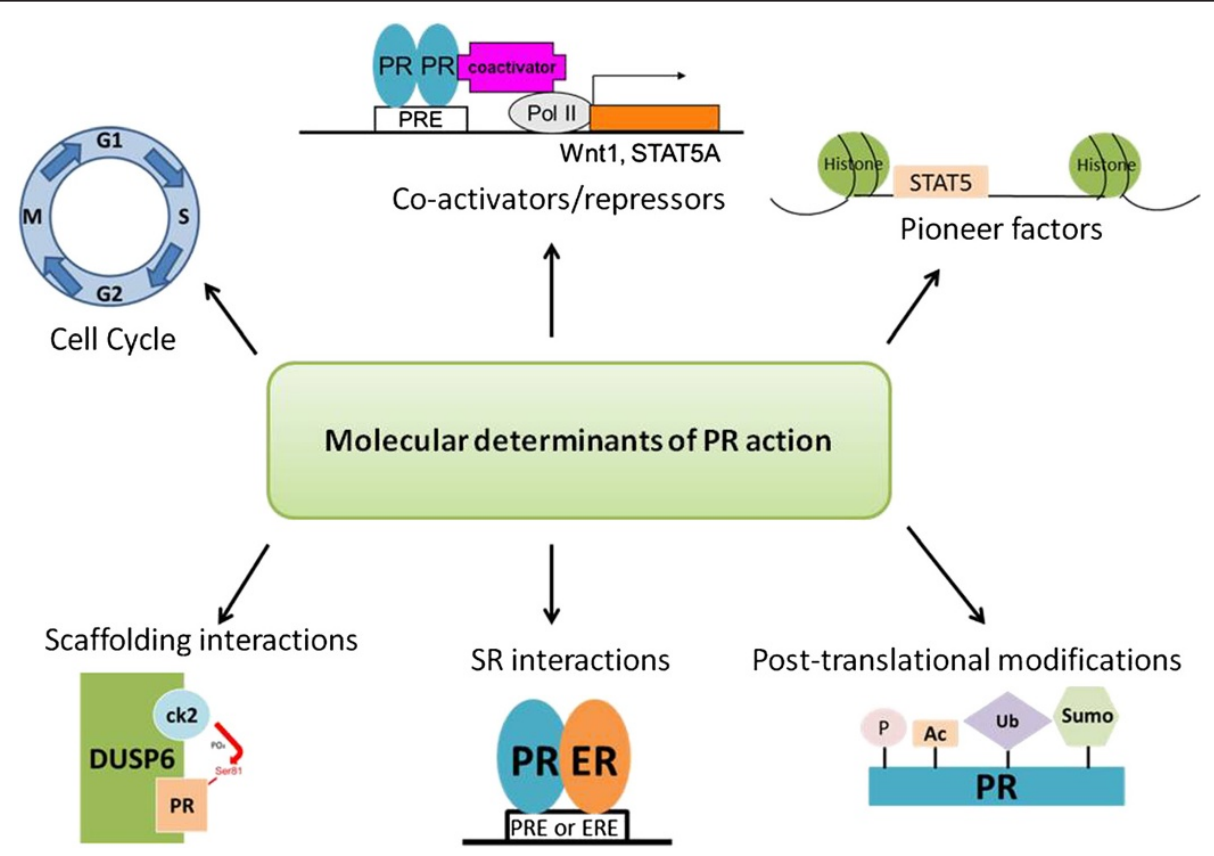

Figure 2 Molecular determinants of progesterone receptor action. Co-activators/repressors: interactions between PR and known transcriptional co-activators (for example, SRC1) and co-repressors (for example, NCOR/SMRT) are a key determinant of promoter specificity. Pioneer factors: interactions with predicted PR pioneer factors (for example, STAT5, putatively) lead to chromatin remodeling, allowing for efficient PR recruitment and subsequent target-gene transcription. Different pioneer factors would be predicted to determine differential PR recruitment. Post-translational modifications: phosphorylation (P), acetylation (Ac), ubiquitination (Ub), and SUMOylation (Sumo) primarily on N-terminal serine and lysine residues dictate receptor localization, turnover, subcellular localization, and promoter selectivity. Steroid receptor (SR) interactions: emerging evidence suggests that interactions between members of the steroid receptor superfamily (such as ER and PR) determine PR target-gene specificity. Scaffolding interactions: PR interaction with proteins acting as scaffolds (such as DUSP6) determine receptor post-translational modifications, thereby contributing to promoter selection. Cell cycle: phosphorylation on select PR serine residues and cell cycle-dependent protein complex formation determine receptor function and recruitment of PR to specific target genes. 
These data suggest that CK2-mediated Ser81 phosphorylation of $\mathrm{PR}$ may activate gene expression programs involved in modulating inflammation related to breast cancer development and progression, including mammary stem cell maintenance and self-renewal.

Recent studies have defined a new mechanism by which CK2 and PR interact. Direct interaction between PR and DUSP6, a negative regulator of the MAPK pathway, is required to achieve phosphorylation on PR Ser81 [8]. This regulation occurs independently of DUSP6 phosphatase activity, suggesting that DUSP6 is acting as a scaffold for the interaction between PR and the kinase that phosphorylates Ser81, CK2. Related to this finding, an interaction between DUSP6 and CK2 has previously been identified [59]. Together, this suggests a model whereby DUSP6 binding to CK2 brings the kinase (CK2) in close proximity to its substrate (PR Ser81), allowing for efficient phosphorylation and subsequent selection of target genes within a given (that is, inflammatory, pro-growth, survival) genetic program.

Cumulatively, in this vignette describing one contextdependent scenario of PR action, there exists cross-talk between mitogenic kinases (that is, CK2 phosphorylation of PR Ser81), MAPK pathway components (that is, DUSP6 interaction with PR is required for Ser81 phosphorylation), phosphorylation-dependent gene regulation (that is, Ser81 phosphorylation is required for PR recruitment to specific subsets of PR target genes), and putative phosphorylationspecific interactions with a pioneer factor/co-factor (that is, JAK/STAT-dependence of PR Ser81-regulated gene expression). PR phosphorylation by CK2 on Ser81 is an exemplary case study of how the molecular determinants of PR action differentially determine receptor function in breast cancer models (Figure 2).

Progesterone receptor clinical significance in breast cancer Luminal breast tumors are characterized by their expression of ER and PR, both of which are good prognostic markers for predicted response to endocrine therapies. Interestingly, analysis of The Cancer Genome Atlas data for the luminal A/B subtype of breast tumors reveals that heterozygous loss of the PR locus occurs in $40 \%$ of luminal tumors, while $25 \%$ of luminal tumors are also heterozygous for the ER locus. However, these tumors are overwhelmingly ER-positive and largely respond well to ER-targeted therapies [60]. Interestingly, PR and ER copy number is often correlated in individual tumors; tumors with altered copy numbers for ER are likely to have changes in PR copy number. Despite these genomic alterations, both PR and ER mRNA levels are similar in luminal tumors that are diploid versus those that have lost an allele at these loci. Thus, gene copy number may not be a robust measure of the functional (that is, protein) readout for these steroid hormone receptors and should be interpreted with caution.
Moreover, complex intra- and inter-tumoral heterogeneity may be reflected in analyses of genomic copy number. Because PR-positive cells release pro-proliferative factors (that is, PR target-gene products) that induce paracrine signaling, a small percentage of PR-positive cells within an individual tumor could have significant effects on tumor stem cell maintenance and/or tumor growth and progression. This is a complex situation that makes PR loci genomic heterozygosity difficult to interpret. Cumulatively, these data underscore the need to gain a much better understanding of PR signaling within the clinical context.

HRT clinical trial data (discussed above) suggest an important role for progestins and $\mathrm{PR}$ as drivers (that is, tumor promoters) of breast cancer cell growth. Progesterone-dependent expression of secreted paracrine factors is required for self-renewal of (PR-null) stem cells in the normal mammary gland [32,37] (see below). PR target genes include soluble factors known to modify cancer stem cells (WNT1 and RANKL). However, the role of PR target genes in the maintenance or expansion of cancer progenitor or stem cells is currently unknown. While a minority of normal (non-pregnant) breast epithelial cells contain steroid hormone receptors, the majority of luminal breast cancers express ER and PR (discussed above); heterogeneous cells within the breast may contain both ER and PR, only ER, or only PR [61]. Interestingly, very few somatic mutations have been identified in ER [62] or PR. With regard to $\mathrm{PR}$, isolated genetic polymorphisms linked to breast and reproductive cancers appear to increase levels of PR-B isoform expression, rather than affect PR transcriptional activity [63-65]. Additionally, the PR-A promoter is more frequently methylated (that is, silenced) relative to the PR-B promoter in advanced endocrine-resistant breast cancers [66]. These data imply that genetic alteration of PR itself is usually not sufficient to promote tumorigenesis. Alternatively, we propose that oncogenic mutations that drive signaling pathways provide the context for heightened ER and PR transcriptional activity. For example, high levels of kinases, such as CK2, CDKs or MAPKs, may induce persistent progesterone-independent phosphorylation of PR-B on serines 81 or 294, respectively, thereby leading to activation of phospho-isoform-specific transcriptional programs shown to be significantly altered in luminal breast cancer $[8,9]$. Therapeutic strategies that target receptormodifying protein kinases (that is, anti-CK2, CDK2 or MAPK) and/or their transcriptional co-factors (that is, STATs, AP1, SP1, FOXO1, FOXA1) are likely to be very successful at treating breast cancer and must remain a direction of robust exploration within the SR field.

Historically, clinical testing of anti-progestins has been limited [42,67-70]. The results of a clinical trial released in 1999 showed promise for anti-progestins as front-line breast cancer endocrine therapy [42]. Although patient accrual in this study was small (19 patients), 67\% of patients 
achieved tumor remission when treated with onapristone, a PR type I antagonist that blocks PR binding to DNA, as front-line endocrine therapy for locally advanced or primary breast cancer [42]. Liver function test abnormalities were seen early in this trial, and for that reason new patient accrual was stopped. These liver-associated effects were likely due to inhibition of GR, a closely related SR. The clinical efficacy of lonaprisan, a type III PR antagonist that promotes PR repression through the recruitment of transcriptional corepressors (while maintaining DNA binding), was measured in a phase II study as second-line therapy for PR-positive breast cancer [70]. The results from this trial were disappointing, and the trial was terminated before full patient accrual. Although a small percentage (14\%) of patients achieved stable disease, no patients achieved complete or partial responses. This trial likely failed for a number of reasons, including lack of patient classification, patients having previous exposure to endocrine therapies, and a lack of mechanistic understanding of PR inhibitor action and isoform specificity. Notably, clinically used anti-progestins that target the ligand-binding domain of PR may fail to block ligand-independent actions of PR (discussed above).

Renewed optimism for the use of anti-progestins to prevent or inhibit breast cancer growth is provided by more recent preclinical studies of anti-progestins in murine mammary tumor models. In a dramatic example, treatment of nulliparous Brca1/Trp53-deficient mice with mifepristone, a PR antagonist, completely inhibited the formation of mammary gland tumors normally observed in virgin mice [71], perhaps via modulation of the stem cell compartment [30,32]. Newer, highly selective anti-progestins, which are currently in development by several pharmaceutical companies, may increase the clinical utility of anti-progestins in breast cancer prevention and treatment and is an area of renewed research interest. Notably, many patients that relapse while on tamoxifen therapy retain expression of $\mathrm{PR}$, underscoring the clinical significance of considering PRs as potentially acting independently of ER in the context of breast cancer progression during estrogen ablation (that is, PR expression is most often used clinically as a measure of ER function) [72,73]. Based on our current understanding of ligand-dependent and ligand-independent (kinase-induced) PR actions, classification of patients based on gene-expression profiling could better identify the subpopulation of patients that would respond well to selective anti-progestins. In addition, cross-talk between ER and PR (or AR), and growth-factor signaling pathways (discussed above) is a likely confounding component of development to endocrine-resistant disease, and should therefore be considered (for example, via the use of pathway-specific gene biomarkers) when selecting antiprogestins as potentially beneficial front-line or secondline therapy [74-76].
As mentioned above (and in Box 1), the clinical significance of PR isoforms is likely vastly under-appreciated. In mammary tissue, PR exists as two primary isoforms, PR-A and PR-B. Although PR-B is required for mammary gland development and PR-A for uterine development, these isoforms are most often co-expressed in the same tissues, typically at a ratio of 1:1. Single isoform expression in tissues is rare [77-79]. Interestingly, in pre-neoplastic lesions and samples from patients with breast cancer, this balanced $A: B$ ratio is often altered, frequently due to apparent loss of PR-B $[78,80]$. Cumulative data from the Lange laboratory has revealed that this imbalance may be explained by phosphorylation-dependent turnover of transcriptionally active PR-B receptors relative to more stable and less active PR-A receptors. PR-B but not PR-A undergoes extensive cross-talk with mitogenic protein kinases $[8,16,45,81,82]$. Thus, PR-B is heavily phosphorylated in response to ligand or via the action of growth factors, and although this isoform-specific phosphorylation (on PR-B Ser294) is linked to high transcriptional activity, it is also coupled to rapid ubiquitin-dependent turnover of the receptor; regulated PR-B turnover is tightly linked to transcriptional activity (that is, stable non-degradable mutants of PR are poor transcriptional activators) [83,84]. Of note, this phosphorylation event (PR-B Ser294) has been detected in a subset of human tumors [9]. Therefore, loss of PR-B, as measured by protein levels in clinical immunohistochemistry tests or western blotting may actually reflect high PR-B transcriptional activity coupled with rapid protein turnover; peak PR target-gene expression (mRNA) is coincident with nearly undetectable PR protein in experimental models [85]. Mouse models (mammary gland) predominantly express PR-A prior to pregnancy. In humans, normal mammary gland function may rely upon balanced expression of the two PR isoforms. Unfortunately, current immunohistochemistry clinical testing for $\mathrm{PR}$ in breast cancer samples does not differentiate between PR-A and PR-B isoforms. Because an imbalance between the two isoforms appears to be linked to cancerous phenotypes, clinical isoform distinction may have great diagnostic potential and should be considered as part of routine luminal cancer work-up.

Emerging data linking progesterone regulation to the expansion of the mammary stem cell compartment highlight the role that PR and progesterone may play in early events in breast cancer. Recent seminal work in murine models has shown that progesterone can induce the rapid expansion of mammary stem cells, a population of SR-negative (that is, ER- and PR-negative) cells located in the basal epithelial compartment of the mammary gland $[32,37]$. Because these cells are PR negative, this expansion likely occurs through the production of paracrine factors secreted by neighboring or nearby PR-positive luminal epithelial cells. Progesterone-dependent expansion of the mammary stem cell population is mediated by key 
PR-target genes, including RANKL and WNT4 [32,37]. Brisken and colleagues have shown that progesteronedependent control of RANKL expression in human tissues is dependent on intact breast tissue microstructure, and have confirmed that RANKL is required for progesteroneinduced proliferation [41]; estrogen is a permissive hormone (for PR expression) in this context. Interestingly, PR-dependent RANKL expression requires STAT5A [50]. This observation is similar to what has been published for PR regulation of WNTs [8], highlighting an emerging role for co-ordinate STAT5/PR regulation of select subsets of PR-target genes related to proliferation and stem cell selfrenewal (see above). Moreover, a PR-positive subpopulation of mammary gland progenitor cells has been recently discovered [61], challenging the current dogma that mammary gland precursors are strictly SR-negative. These exciting findings suggest that this long-lived population of cells, one that is exquisitely sensitive to mutagenic events, can expand in response to progesterone in both a paracrine and autocrine fashion [36]. Notably, these PR-positive mammary stem cells are devoid of ER protein or mRNA expression, further underscoring the need for understanding PR action as independent of ER in this context.

\section{Conclusions}

Recent clinical and preclinical studies clearly demonstrate the significance of fully understanding the determinants of context-dependent PR action. They not only challenge the current clinical diagnostic paradigm in which PR is only used as a marker of ER transcriptional activity, but also support a renewed interest in understanding $P R$ as a driver of breast tumor progression and thus a potentially very useful target for improved breast cancer therapy $[1,86]$. In this review, we have highlighted the concept that gene-expression analyses linked to PR actions suggest different transcriptional programs are activated in response to specific posttranslational modifications (phosphorylation events) and protein-protein interactions. Although these unique PR gene signatures highlight functional differences between modified PRs and their components, the overlap between these (predominantly proliferative) programs supports a strong role for PR in early tumor progression toward more aggressive cancer phenotypes, and in some cases, even highlights a phospho-PR gene signature associated with poor response to endocrine treatment [9]. Therefore, gene signatures that define PR action will likely provide a useful paired diagnostic for clinically applied selective anti-progestins. We conclude that PR function is highly dependent on the molecular context, which is defined by such factors as protein kinase activity (as a major input to receptor post-translational modifications), co-factor availability, and the presence of progesterone and other steroid hormone levels and receptors (Figure 2). Future therapeutic approaches should consider targeting receptor-modifying activities in place of or in conjunction with anti-hormone therapies. With progesterone emerging as the primary mitogen in the adult breast (wherein estrogen is permissive for PR expression), understanding PR function and identifying or targeting modifiers of PR action are of critical importance to advancing the treatment of breast cancer.

\section{Abbreviations}

AR: androgen receptor; ER: estrogen receptor; GR: glucocorticoid receptor; HRT: hormone-replacement therapy; PR: progesterone receptor; SR: steroid receptor.

\section{Competing interests}

CAL receives consulting income from Arno Therapeutics, Inc. This interest has been reviewed and managed by the University of Minnesota in accordance with its Conflict of Interest policies. CRH declares that she has no competing interests.

\section{Authors' contributions}

$\mathrm{CRH}$ and CAL together led the initial design and conception of the manuscript. CRH led the writing of the first and all subsequent drafts of the manuscript. CAL contributed significant written and editorial inputs to the manuscript at every stage. Both authors read and approved the final manuscript.

\section{Authors' information}

CAL joined the University of Minnesota (Departments of Medicine and Pharmacology) faculty in 1999. Her research is focused on steroid hormone action in breast cancer progression. Her laboratory studies the role of cross-talk between growth factor-mediated signaling pathways and steroid hormone receptors, using the human progesterone receptor as a model receptor. CAL holds the Tickle Family Land Grant Endowed Chair of Breast Cancer Research at the University of Minnesota. She is the Director of The Cancer Biology Training Grant (T32) and the Cell Signaling Program Lead within the Masonic Cancer Center. CAL is Editor-in-Chief of the journal Hormones and Cancer (jointly held by The Endocrine Society and Springer). $\mathrm{CRH}$ is a senior post-doctoral fellow in the laboratory of CAL.

\section{Acknowledgements}

The authors would like to thank Dr. Andrea R. Daniel (Minnesota) for her critical review of this manuscript, and Michael Freeman (Minnesota) for editorial assistance.

Received: 17 October 2013 Accepted: 21 January 2014

Published: 20 Feb 2014

\section{References}

1. Brisken C: Progesterone signalling in breast cancer: a neglected hormone coming into the limelight. Nat Rev Cancer 2013, 13:385-396.

2. Kraus WL, Montano MM, Katzenellenbogen BS: Cloning of the rat progesterone receptor gene 5'-region and identification of two functionally distinct promoters. Mol Endocrinol 1993, 7:1603-1616.

3. Hill KK, Roemer SC, Churchill ME, Edwards DP: Structural and functional analysis of domains of the progesterone receptor. Mol Cell Endocrinol 2012, 348:418-429.

4. Kastner P, Krust A, Turcotte B, Stropp U, Tora L, Gronemeyer H, Chambon P: Two distinct estrogen-regulated promoters generate transcripts encoding the two functionally different human progesterone receptor forms $\mathrm{A}$ and B. Embo J 1990, 9:1603-1614.

5. Owen Gl, Richer JK, Tung L, Takimoto G, Horwitz KB: Progesterone regulates transcription of the $\mathrm{p} 21$ (WAF1) cyclin-dependent kinase inhibitor gene through Sp1 and CBP/p300. J Biol Chem 1998, 273:10696-10701.

6. Stoecklin E, Wissler M, Schaetzle D, Pfitzner E, Groner B: Interactions in the transcriptional regulation exerted by Stat 5 and by members of the steroid hormone receptor family. J Steroid Biochem Mol Biol 1999, 69:195-204.

7. Cicatiello L, Addeo R, Sasso A, Altucci L, Petrizzi VB, Borgo R, Cancemi M, Caporali S, Caristi S, Scafoglio C, et al: Estrogens and progesterone promote persistent CCND1 gene activation during G1 by inducing transcriptional derepression via c-Jun/c-Fos/estrogen receptor (progesterone receptor) 
complex assembly to a distal regulatory element and recruitment of cyclin D1 to its own gene promoter. Mol Cell Biol 2004, 24:7260-7274.

8. Hagan CR, Knutson TP, Lange CA: A common docking domain in progesterone receptor-B links DUSP6 and CK2 signaling to proliferative transcriptional programs in breast cancer cells. Nucleic Acids Res 2013, 41:8962-8942.

9. Knutson TP, Daniel AR, Fan D, Silverstein KA, Covington KR, Fuqua SA, Lange CA: Phosphorylated and sumoylation-deficient progesterone receptors drive proliferative gene signatures during breast cancer progression. Breast Cancer Res 2012, 14:R95.

10. McKenna NJ, Lanz RB, O'Malley BW: Nuclear receptor coregulators: cellular and molecular biology. Endocr Rev 1999, 20:321-344.

11. Daniel AR, Faivre EJ, Lange CA: Phosphorylation-dependent antagonism of sumoylation derepresses progesterone receptor action in breast cancer cells. Mol Endocrinol 2007, 21:2890-2906.

12. Lange CA, Shen T, Horwitz KB: Phosphorylation of human progesterone receptors at serine- 294 by mitogen-activated protein kinase signals their degradation by the 265 proteasome. Proc Natl Acad Sci U S A 2000, 97:1032-1037

13. Weigel NL, Bai W, Zhang Y, Beck CA, Edwards DP, Poletti A: Phosphorylation and progesterone receptor function. J Steroid Biochem Mol Biol 1995, 53:509-514.

14. Daniel AR, Gaviglio AL, Czaplicki LM, Hillard CJ, Housa D, Lange CA: The progesterone receptor hinge region regulates the kinetics of transcriptional responses through acetylation, phosphorylation, and nuclear retention. Mol Endocrinol 2011, 24:2126-2138.

15. Pierson-Mullany LK, Lange CA: Phosphorylation of progesterone receptor serine $\mathbf{4 0 0}$ mediates ligand-independent transcriptional activity in response to activation of cyclin-dependent protein kinase 2. Mol Cell Biol 2004, 24:10542-10557.

16. Hagan CR, Regan TM, Dressing GE, Lange CA: CK2-dependent phosphorylation of progesterone receptors (PR) on Ser81 regulates PR-B isoform-specific target gene expression in breast cancer cells CK2. Mol Cell Biol 2011, 31:2439-2452.

17. Faivre EJ, Daniel AR, Hillard CJ, Lange CA: Progesterone receptor rapid signaling mediates serine 345 phosphorylation and tethering to specificity protein 1 transcription factors. Mol Endocrinol 2008, 22:823-837.

18. Ballare C, Uhrig M, Bechtold T, Sancho E, Di Domenico M, Migliaccio A, Auricchio $\mathrm{F}$, Beato M: Two domains of the progesterone receptor interact with the estrogen receptor and are required for progesterone activation of the c-Src/Erk pathway in mammalian cells. Mol Cell Biol 2003, 23:1994-2008.

19. Boonyaratanakornkit V, Scott MP, Ribon V, Sherman L, Anderson SM, Maller $J$ L, Miller WT, Edwards DP: Progesterone receptor contains a proline-rich motif that directly interacts with $\mathrm{SH} 3$ domains and activates c-Src family tyrosine kinases. Mol Cell 2001, 8:269-280.

20. Diaz Flaque MC, Vicario R, Proietti CJ, Izzo F, Schillaci R, Elizalde PV: Progestin drives breast cancer growth by inducing p21(CIP1) expression through the assembly of a transcriptional complex among Stat3, progesterone receptor and ErbB-2. Steroids 2013, 78:559-567.

21. Narayanan R, Adigun AA, Edwards DP, Weigel NL: Cyclin-dependent kinase activity is required for progesterone receptor function: novel role for cyclin A/Cdk2 as a progesterone receptor coactivator. Mol Cell Biol 2005, 25:264-277.

22. Beral V: Breast cancer and hormone-replacement therapy in the Million Women Study. Lancet 2003, 362:419-427.

23. Chlebowski RT, Anderson GL, Gass M, Lane DS, Aragaki AK, Kuller LH, Manson JE, Stefanick ML, Ockene J, Sarto GE, et al: Estrogen plus progestin and breast cancer incidence and mortality in postmenopausal women. JAMA 2010, 304:1684-1692.

24. Birrell SN, Butler LM, Harris JM, Buchanan G, Tilley WD: Disruption of androgen receptor signaling by synthetic progestins may increase risk of developing breast cancer. FASEB J 2007, 21:2285-2293.

25. Courtin A, Communal L, Vilasco M, Cimino D, Mourra N, de Bortoli M, Taverna D, Faussat AM, Chaouat M, Forgez P, et al: Glucocorticoid receptor activity discriminates between progesterone and medroxyprogesterone acetate effects in breast cells. Breast Cancer Res Treat 2012, 131:49-63.

26. Fournier A, Berrino F, Riboli E, Avenel V, Clavel-Chapelon F: Breast cancer risk in relation to different types of hormone replacement therapy in the E3N-EPIC cohort. Int J Cancer 2005, 114:448-454.

27. Lyytinen $\mathrm{H}$, Pukkala E, Ylikorkala O: Breast cancer risk in postmenopausal women using estradiol-progestogen therapy. Obstet Gynecol 2009, 113:65-73.

28. Lanari C, Lamb CA, Fabris VT, Helguero LA, Soldati R, Bottino MC, Giulianelli S, Cerliani JP, Wargon V, Molinolo A: The MPA mouse breast cancer model: evidence for a role of progesterone receptors in breast cancer. Endocr Relat Cancer 2009, 16:333-350.

29. Lanari C, Molinolo AA: Progesterone receptors-animal models and cell signalling in breast cancer. Diverse activation pathways for the progesterone receptor: possible implications for breast biology and cancer. Breast Cancer Res 2002, 4:240-243.

30. Horwitz KB, Dye WW, Harrell JC, Kabos P, Sartorius CA: Rare steroid receptor-negative basal-like tumorigenic cells in luminal subtype human breast cancer xenografts. Proc Natl Acad Sci U S A 2008, 105:5774-5779.

31. Horwitz KB, Sartorius CA: Progestins in hormone replacement therapies reactivate cancer stem cells in women with preexisting breast cancers: a hypothesis. J Clin Endocrinol Metab 2008, 93:3295-3298.

32. Joshi PA, Jackson HW, Beristain AG, Di Grappa MA, Mote PA, Clarke CL, Stingl J, Waterhouse PD, Khokha R: Progesterone induces adult mammary stem cell expansion. Nature 2010, 465:803-807.

33. Santen RJ: Risk of breast cancer with progestins: critical assessment of current data. Steroids 2003, 68:953-964.

34. Hofseth $\amalg$, Raafat AM, Osuch JR, Pathak DR, Slomski CA, Haslam SZ: Hormone replacement therapy with estrogen or estrogen plus medroxyprogesterone acetate is associated with increased epithelial proliferation in the normal postmenopausal breast. J Clin Endocrinol Metab 1999, 84:4559-4565.

35. Santen RJ: Menopausal hormone therapy and breast cancer. J Steroid Biochem Mol Biol 2013, 2013:2013.

36. Beleut M, Rajaram RD, Caikovski M, Ayyanan A, Germano D, Choi Y, Schneider $\mathrm{P}$, Brisken $\mathrm{C}$ : Two distinct mechanisms underlie progesteroneinduced proliferation in the mammary gland. Proc Natl Acad Sci U S A 2010, 107:2989-2994.

37. Asselin-Labat ML, Shackleton M, Stingl J, Vaillant F, Forrest NC, Eaves CJ, Visvader JE, Lindeman GJ: Steroid hormone receptor status of mouse mammary stem cells. J Natl Cancer Inst 2006, 98:1011-1014.

38. Groshong SD, Owen Gl, Grimison B, Schauer IE, Todd MC, Langan TA, Sclafani RA, Lange CA, Horwitz KB: Biphasic regulation of breast cancer cell growth by progesterone: role of the cyclin-dependent kinase inhibitors, p21 and p27(Kip1). Mol Endocrinol 1997, 11:1593-1607.

39. Clarke RB, Howell A, Anderson E: Estrogen sensitivity of normal human breast tissue in vivo and implanted into athymic nude mice: analysis of the relationship between estrogen-induced proliferation and progesterone receptor expression. Breast Cancer Res Treat 1997, 45:121-133.

40. Communal L, Vilasco M, Hugon-Rodin J, Courtin A, Mourra N, Lahlou N, Dumont S, Chaouat M, Forgez P, Gompel A: Ulipristal acetate does not impact human normal breast tissue. Hum Reprod 2012, 27:2785-2798.

41. Tanos T, Sflomos G, Echeverria PC, Ayyanan A, Gutierrez M, Delaloye JF, Raffoul W, Fiche M, Dougall W, Schneider P, et al: Progesterone/RANKL is a major regulatory axis in the human breast. Sci Trans/ Med 2013, 5:182ra155.

42. Robertson JF, Willsher PC, Winterbottom L, Blamey RW, Thorpe S: Onapristone, a progesterone receptor antagonist, as first-line therapy in primary breast cancer. Eur J Cancer 1999, 35:214-218.

43. Hagan CR, Daniel AR, Dressing GE, Lange CA: Role of phosphorylation in progesterone receptor signaling and specificity. Mol Cell Endocrinol 2012, 357:43-49.

44. Dressing GE, Hagan CR, Knutson TP, Daniel AR, Lange CA: Progesterone receptors act as sensors for mitogenic protein kinases in breast cancer models. Endocr Relat Cancer 2009, 16:351-361.

45. Daniel AR, Faivre EJ, Lange CA: Phosphorylation-dependent antagonism of sumoylation derepresses progesterone receptor action in breast cancer cells. Mol Endocrinol 2007, 21:2890-2906.

46. Daniel AR, Lange CA: Protein kinases mediate ligand-independent derepression of sumoylated progesterone receptors in breast cancer cells. Proc Natl Acad Sci U S A 2009, 106:14287-14292.

47. Jozwik KM, Carroll JS: Pioneer factors in hormone-dependent cancers. Nat Rev Cancer 2012, 12:381-385.

48. Magnani L, Eeckhoute J, Lupien M: Pioneer factors: directing transcriptional regulators within the chromatin environment. Trends Genet 2011, 27:465-474.

49. Clarke CL, Graham JD: Non-overlapping progesterone receptor cistromes contribute to cell-specific transcriptional outcomes. PLoS One 2012, 7:e35859.

50. Obr AE, Grimm SL, Bishop KA, Pike JW, Lydon JP, Edwards DP: Progesterone receptor and Stat5 signaling crosstalk through RANKL in mammary epithelial cells. Mol Endocrinol 2013, 27:1808-1824. 
51. Peters AA, Buchanan G, Ricciardelli C, Bianco-Miotto T, Centenera MM, Harris JM, Jindal S, Segara D, Jia L, Moore NL, et al: Androgen receptor inhibits estrogen receptor-alpha activity and is prognostic in breast cancer. Cancer Res 2009, 69:6131-6140.

52. Need EF, Selth LA, Harris TJ, Birrell SN, Tilley WD, Buchanan G: Research resource: interplay between the genomic and transcriptional networks of androgen receptor and estrogen receptor alpha in luminal breast cancer cells. Mol Endocrinol 2012, 26:1941-1952.

53. Giulianelli S, Vaque JP, Soldati R, Wargon V, Vanzulli SI, Martins R, Zeitlin E, Molinolo AA, Helguero LA, Lamb CA, et al: Estrogen receptor alpha mediates progestin-induced mammary tumor growth by interacting with progesterone receptors at the cyclin D1/MYC promoters. Cancer Res 2012, 72:2416-2427.

54. Daniel AR, Gaviglio AL, Knutson TP, Ostrander JH, D'Assoro AB, Ravindranathan $P$, Peng Y, Raj GV, Yee D, Lange CA: Progesterone receptor-B enhances estrogen responsiveness of breast cancer cells via scaffolding PELP1- and estrogen receptor-containing transcription complexes. Oncogene 2014. doi:10.1038/onc.2013.579. [Epub ahead of print].

55. Tawfic S, Yu S, Wang H, Faust R, Davis A, Ahmed K: Protein kinase CK2 signal in neoplasia. Histol Histopathol 2001, 16:573-582.

56. Guerra B, Issinger OG: Protein kinase CK2 in human diseases. Curr Med Chem 2008, 15:1870-1886.

57. Meggio F, Pinna LA: One-thousand-and-one substrates of protein kinase CK2? FASEB J 2003, 17:349-368.

58. Zhang Y, Beck CA, Poletti A, Edwards DP, Weigel NL: Identification of phosphorylation sites unique to the $B$ form of human progesterone receptor. In vitro phosphorylation by casein kinase II. J Biol Chem 1994, 269:31034-31040

59. Castelli M, Camps M, Gillieron C, Leroy D, Arkinstall S, Rommel C, Nichols A MAP kinase phosphatase 3 (MKP3) interacts with and is phosphorylated by protein kinase CK2alpha. J Biol Chem 2004, 279:44731-44739.

60. Cancer Genome Atlas Network: Comprehensive molecular portraits of human breast tumours. Nature 2012, 490:61-70

61. Hilton HN, Graham JD, Kantimm S, Santucci N, Cloosterman D, Huschtscha LI, Mote PA, Clarke CL: Progesterone and estrogen receptors segregate into different cell subpopulations in the normal human breast. $\mathrm{Mo} / \mathrm{Cell}$ Endocrinol 2012, 361:191-201.

62. Fuqua SA, Wiltschke $C$, Zhang QX, Borg A, Castles CG, Friedrichs WE, Hopp T, Hilsenbeck S, Mohsin S, O'Connell P, et al: A hypersensitive estrogen receptor-alpha mutation in premalignant breast lesions. Cancer Res 2000, 60:4026-4029

63. Pooley KA, Healey CS, Smith PL, Pharoah PD, Thompson D, Tee L, West J, Jordan C, Easton DF, Ponder BA, et al: Association of the progesterone receptor gene with breast cancer risk: a single-nucleotide polymorphism tagging approach. Cancer Epidemiol Biomarkers Prev 2006, 15:675-682.

64. De Vivo I, Huggins GS, Hankinson SE, Lescault PJ, Boezen M, Colditz GA, Hunter DJ: A functional polymorphism in the promoter of the progesterone receptor gene associated with endometrial cancer risk. Proc Natl Acad Sci U S A 2002, 99:12263-12268.

65. Terry KL, De Vivo I, Titus-Ernstoff L, Sluss PM, Cramer DW: Genetic variation in the progesterone receptor gene and ovarian cancer risk. Am J Epidemiol 2005, 161:442-451.

66. Pathiraja TN, Shetty PB, Jelinek J, He R, Hartmaier R, Margossian AL, Hilsenbeck SG, Issa JP, Oesterreich S: Progesterone receptor isoform-specific promoter methylation: association of PRA promoter methylation with worse outcome in breast cancer patients. Clin Cancer Res 2011, 17:4177-4186.

67. Romieu G, Maudelonde T, Ulmann A, Pujol H, Grenier J, Cavalie G, Khalaf S, Rochefort $\mathrm{H}$ : The antiprogestin RU486 in advanced breast cancer: preliminary clinical trial. Bull Cancer 1987, 74:455-461.

68. Klijn JG, de Jong FH, Bakker GH, Lamberts SW, Rodenburg CJ, Alexieva-Figusch J: Antiprogestins, a new form of endocrine therapy for human breast cancer. Cancer Res 1989, 49:2851-2856.

69. Perrault D, Eisenhauer EA, Pritchard KI, Panasci L, Norris B, Vandenberg T, Fisher B: Phase II study of the progesterone antagonist mifepristone in patients with untreated metastatic breast carcinoma: a National Cancer Institute of Canada Clinical Trials Group study. J Clin Oncol 1996, 14:2709-2712.

70. Jonat W, Bachelot T, Ruhstaller T, Kuss I, Reimann U, Robertson JF: Randomized phase II study of lonaprisan as second-line therapy for progesterone receptor-positive breast cancer. Ann Oncol 2013, 24:2543-2548.
71. Poole AJ, Li Y, Kim Y, Lin SC, Lee WH, Lee EY: Prevention of Brca1-mediated mammary tumorigenesis in mice by a progesterone antagonist. Science 2006, 314:1467-1470.

72. Encarnacion CA, Ciocca DR, McGuire WL, Clark GM, Fuqua SA, Osborne CK: Measurement of steroid hormone receptors in breast cancer patients on tamoxifen. Breast Cancer Res Treat 1993, 26:237-246.

73. Johnston SR, Saccani-Jotti G, Smith IE, Salter J, Newby J, Coppen M, Ebbs $S R$, Dowsett M: Changes in estrogen receptor, progesterone receptor, and pS2 expression in tamoxifen-resistant human breast cancer. Cancer Res 1995, 55:3331-3338.

74. Hayes E, Nicholson RI, Hiscox S: Acquired endocrine resistance in breast cancer: implications for tumour metastasis. Front Biosci (Landmark Ed) 2011, 16:838-848.

75. Cleator SJ, Ahamed E, Coombes RC, Palmieri C: A 2009 update on the treatment of patients with hormone receptor-positive breast cancer. Clin Breast Cancer 2009, 9:S6-S17.

76. Pierson-Mullany LK, Skildum A, Faivre E, Lange CA: Cross-talk between growth factor and progesterone receptor signaling pathways: implications for breast cancer cell growth. Breast Dis 2003, 18:21-31.

77. Mote PA, Balleine RL, McGowan EM, Clarke CL: Colocalization of progesterone receptors $A$ and $B$ by dual immunofluorescent histochemistry in human endometrium during the menstrual cycle. J Clin Endocrinol Metab 1999, 84:2963-2971.

78. Mote PA, Bartow S, Tran N, Clarke CL: Loss of co-ordinate expression of progesterone receptors $A$ and $B$ is an early event in breast carcinogenesis. Breast Cancer Res Treat 2002, 72:163-172.

79. Mote PA, Graham JD, Clarke CL: Progesterone receptor isoforms in normal and malignant breast. Ernst Schering Found Symp Proc 2007, 1:77-107.

80. Graham JD, Yeates C, Balleine RL, Harvey SS, Milliken JS, Bilous AM, Clarke $\mathrm{CL}$ : Characterization of progesterone receptor $\mathrm{A}$ and $\mathrm{B}$ expression in human breast cancer. Cancer Res 1995, 55:5063-5068.

81. Boonyaratanakornkit V, McGowan E, Sherman L, Mancini MA, Cheskis BJ, Edwards DP: The role of extranuclear signaling actions of progesterone receptor in mediating progesterone regulation of gene expression and the cell cycle. Mol Endocrinol 2007, 21:359-375.

82. Clemm DL, Sherman L, Boonyaratanakornkit V, Schrader WT, Weigel NL, Edwards DP: Differential hormone-dependent phosphorylation of progesterone receptor $A$ and $B$ forms revealed by a phosphoserine site-specific monoclonal antibody. Mol Endocrinol 2000, 14:52-65.

83. Qiu M, Lange CA: MAP kinases couple multiple functions of human progesterone receptors: degradation, transcriptional synergy, and nuclear association. J Steroid Biochem Mol Biol 2003, 85:147-157.

84. Qiu M, Olsen A, Faivre E, Horwitz KB, Lange CA: Mitogen-activated protein kinase regulates nuclear association of human progesterone receptors. Mol Endocrinol 2003, 17:628-642.

85. Faivre EJ, Lange CA: Progesterone receptors upregulate Wnt-1 to induce epidermal growth factor receptor transactivation and c-Src-dependent sustained activation of Erk1/2 mitogen-activated protein kinase in breast cancer cells. Mol Cell Biol 2007, 27:466-480.

86. Lanari C, Wargon V, Rojas P, Molinolo AA: Antiprogestins in breast cancer treatment: are we ready? Endocr Relat Cancer 2012, 19:R35-R50.

\subsection{6/1741-7015-12-32}

Cite this article as: Hagan and Lange: Molecular determinants of context-dependent progesterone receptor action in breast cancer. BMC Medicine 2014, 12:32

\section{Submit your next manuscript to BioMed Central and take full advantage of:}

- Convenient online submission

- Thorough peer review

- No space constraints or color figure charges

- Immediate publication on acceptance

- Inclusion in PubMed, CAS, Scopus and Google Scholar

- Research which is freely available for redistribution 